\title{
Índice de sensibilidade ao óleo em ambientes fluviais (ISLF) aplicado aos sistemas deltaicos: proposta metodológica
}

\author{
Marilia Kabke WALLY \& João Luiz NICOLODI
}

Laboratório de Oceanografia Geológica, Instituto de Oceanografia, Universidade Federal do Rio Grande, Avenida Itália, Km 08, CEP 96203-900, Rio Grande, RS, Brasil (mariliakw@furg.br, joaonicolodi@furg.br).

\begin{abstract}
Resumo. Derrames de óleo e derivados causam impactos sobre a vida aquática, atingindo também atividades socioeconômicas, como a pesca e o turismo. As Cartas de Sensibilidade ao Óleo são instrumentos para orientação à resposta em casos de acidentes, uma vez que fornecem subsídios necessários à tomada de decisões de contingência. Contudo, a atual metodologia destas Cartas é desenvolvida para ambientes costeiros e marinhos. Rios e regiões estuarinas possuem características distintas, as quais não são consideradas na classificação. Este trabalho desenvolveu um índice de sensibilidade ao óleo para ambientes fluviais, aplicado à região do delta do Rio Jacuí, Rio Grande do Sul (Brasil), local de considerável tráfego de embarcações que transportam derivados de petróleo para o Polo Petroquímico de Triunfo. A metodologia aplicada consistiu na identificação e adaptação de métodos específicos para o ambiente fluvial e definição dos critérios de sensibilidade aplicados na classificação. As principais variáveis consideradas foram declividade/substrato da margem e tipo de vegetação associada, já que estas interferem diretamente no comportamento do óleo. 0 índice desenvolvido classificou as feições em um índice (ISLF) com 10 classes específicas de sensibilidade ao óleo, divididas em dois grupos: sem vegetação e margens vegetadas, sendo estas divididas conforme a importância ecológica e o porte. $\mathrm{O}$ índice desenvolvido contribui para a discussão sobre o aperfeiçoamento deste tipo de classificação, tornando-a mais adequada para os ambientes fluviais e deltaicos, tendo, ainda, potencial para contribuir na discussão sobre a gestão de contingência à incidentes com óleo no país.
\end{abstract}

Palavras-chave. Sensibilidade ao Óleo; Mapeamento Ambiental; Cartas SAO; Delta do Jacuí, RS.

\begin{abstract}
OIL SENSITIVITY INDEX IN FLUVIAL ENVIRONMENTS (ISLF) APPLIED TO DELTAIC SYSTEMS: METHODOLOGICAL PROPOSAL. The risk of oil spills is common in fluvial environments. These spills have impacts on aquatic life and affect socioeconomic activities such as fishing and tourism. Maps of Environmental Sensitivity (SAO Charts) are official instruments that can guide responses in cases of oil spill accidents, by providing necessary subsidies to take contingency decisions. However, the current methodology for the development of SAO Charts is designed for employment in coastal and marine environments. Rivers and estuarine regions have particular geomorphological and hydrodynamic characteristics that differ from marine environments, and therefore are not properly classified. The aim of this study was to establish an oil sensitivity index for fluvial environments, applied to the Jacuí river delta region, RS. The study area has a daily traffic of vessels loaded with oil byproducts that are transported to the Triunfo Petrochemical Complex. This is an area of high environmental sensitivity because there are several islands and canals around the delta region. The methodology consisted of the identification of the existence and application of already established methods for the riverine environment, features systematization of the study area and definition of sensitivity criteria for classification. The main considered variables were the slope and substrate of the margin and associated vegetation types, as they interfere directly with the behavior of the spilled oil. The index developed here expects to perform a more appropriate classification of the riverine environments of concern. This work also aims to contribute to the contingency management in Brazil and incentivate dialogues about oil sensitivity.
\end{abstract}

Keywords. Oil sensibility; Environmental Mapping; Jacui Delta. 


\section{Introdução}

Há um risco inerente ao transporte de combustíveis fósseis de que derramamentos de óleo e derivados possam ocorrer ocasionando danos aos ambientes. Particularmente, os ambientes fluviais são muito suscetíveis a este risco por meio de acidentes com navios, trens, caminhões e dutos. Estes derramamentos causam impactos sobre a vida aquática, atingindo também atividades socioeconômicas, como a pesca e o turismo (Adler \& Inbar, 2007; Hellea et al. 2011; Azevedo et al. 2017; Nelson \& Grubesic, 2017; Parviainen et al. 2019). Em um dos exemplos mais graves ocorridos no Brasil, em 2000, cerca de 4 milhões de litros de óleo cru atingiram o Rio Barigüí e o Rio Iguaçu no Paraná, trazendo grandes impactos econômicos e ecológicos para a região. Este vazamento originou-se em um duto na Refinaria Getúlio Vargas em Araucária, Paraná (Melo et al., 2003).

Em termos de tipologia, o IBAMA, um dos órgãos responsáveis pela fiscalização da atividade, registrou (até o ano de 2013) 195 acidentes ambientais nas rodovias brasileiras, 101 em ferrovias, 81 em plataformas, 61 em embarcações, 59 em indústrias, 32 em dutos, 28 envolvendo armazenamento ou depósito de produtos perigosos, 14 em portos e terminais, 10 em postos de combustíveis, 8 em barragens, e 5 em refinarias, todos envolvendo produtos perigosos (IBAMA, 2014). O "derramamento de líquidos" foi o evento mais registrado desde 2006 sendo que em 2013 foram registradas 377 ocorrências (51,5\% do total de registros) e em 2014, 340 (trezentos e quarenta) ocorrências (46\% do total), sendo que quase a totalidade deste material líquido vazado é derivada de produtos de petróleo (IBAMA, 2015). Cabe ressaltar que não há informações atualizadas sobre este tema nos canais oficiais dos órgãos de meio ambiente após o ano de 2015.

Estes dados mostram que acidentes ocorrem não apenas nas etapas de extração e produção, mas também na logística do petróleo e seus derivados. Já a Agência Nacional de Petróleo e Gás (ANP) informa, em uma abordagem distinta, mas não menos importante, que a média da taxa de incidentes por milhão de horas trabalhadas nas instalações de exploração e produção offshore no Brasil foi de 21,9 ao ano, entre 2014 e 2018 (ANP, 2020).

O Brasil, por meio da assinatura de convenções internacionais, mantém o compromisso de possuir uma estrutura nacional de combate à poluição por óleo que atue na prevenção, controle e fiscalização para a proteção do ambiente marinho. A partir da Lei no 9.966/2000, portos organizados, plataformas e demais instalações portuárias devem possuir planos de emergência para combate à poluição poróleo e substâncias nocivas ou perigosas. Estes planos consistem em um conjunto de ações de resposta desencadeadas imediatamente após o incidente. Um dos principais instrumentos deste plano é o conjunto de Cartas de Sensibilidade ao Óleo - Cartas SAO, elaboradas para as áreas potencialmente atingidas no caso de derramamento de óleo.

As Cartas SAO fornecem subsídios necessários à tomada de decisões imediatas sobre prioridades de proteção e definição da estratégia de controle mais adequada a cada situação específica. Esta é a metodologia oficial utilizada pelo governo brasileiro, sendo que maiores detalhes podem ser observados no documento "Especificações e Normas Técnicas para a Elaboração de Cartas de Sensibilidade Ambiental para Derrames de Óleo" (MMA, 2007). Cabe ressaltar que este arcabouço técnico foi desenvolvido para ambientes costeiros e marinhos, não considerando que rios e regiões estuarinas possuem características geomorfológicas e hidrodinâmicas distintas e, deste modo, não podem ser analisados e classificados a partir dos mesmos critérios, se tomada como referência a metodologia padrão.

No âmbito das Cartas SAO, a variável Sensibilidade é classificada por meio do Índice de Sensibilidade do Litoral (ISL), que leva em consideração as características geomorfológicas, como o grau de exposição à energia de ondas e marés, a declividade do litoral e o tipo do substrato. A escala varia de 1 a 10 em um grau crescente de sensibilidade. Uma das discussões mais prementes em relação a este índice diz respeito às variáveis que o conformam. As características geomorfológicas, aliadas à 
hidrodinâmica, com maior destaque para grau de exposição de ondas e marés, são preponderantes na definição da sensibilidade representada pelo ISL. Ainda que outros conjuntos de dados constem como informações nas Cartas SAO, tais como os recursos biológicos e as atividades socioeconômicas, estes não fazem parte da composição do índice.

Tal composição é discutida por alguns autores como Campo (2017), Castanedo et al. (2009), IMO (2016) e Vasconcelos et al. (2010). Outros autores vêm avançando na elaboração de novos índices no qual as já utilizadas variáveis geomorfológicas e hidrodinâmicas são relacionadas às variáveis biológicas (Fattal et al. 2010; Nelson et al. 2015; Cai et al. 2015; Kankara et al. 2016; Lawal \& Oyegun 2017). No Brasil, Marinho \& Nicolodi (2019) apresentaram proposta de um Índice Integrado de Sensibilidade do Litoral (IISL), onde a integração de dois conjuntos de variáveis representados pelos Índice Geomorfológico de Sensibilidade (IG) e Índice Biológico de Sensibilidade (IB) tiveram suas variáveis definidas por metodologia própria permitindo a composição desse novo índice (IISL).

Outra questão premente de avaliação e discussão é a adaptação destes índices para os ambientes fluviais, estuarinos e deltaicos. Tal demanda parte do fato de que este tipo de mapeamento de áreas sensíveis a derramamento de óleo foi criado e implantado especificamente em regiões litorâneas na década de 70 nos Estados Unidos (Michel et al., 1994). O trabalho de Gundlach \& Hayes (1978) criou o primeiro índice de sensibilidade ambiental associando as características morfológicas do ambiente e a capacidade de autodepuração, sendo que as regiões fluviais e lacustres foram classificadas a partir de ajustes específicos nos métodos para áreas costeiras. Por sua vez, o Canadá mapeou regiões lacustres fazendo uma adaptação do modelo de persistência do óleo marinho para os Grandes Lagos. Já os Estados Unidos extrapolaram o índice de sensibilidade ambiental marinho para classificar os principais rios (Michel et al., 1994).

Os primeiros trabalhos que abordam a problemática da metodologia para a sensibilidade fluvial são os de Adams et al. (1983) e Baca et al. (1985), os quais classificaram a sensibilidade ambiental a partir de variáveis como: tempo de recuperação dos habitats; persistência do óleo; importância das espécies; singularidade dos habitats e grau de danos ao habitat decorrentes da limpeza.

Um índice fluvial utilizado pela agência norte americana NOAA nos mapeamentos de grandes rios foi proposto por Hayes et al. (1995). Esta classificação foi desenvolvida com base no entendimento dos processos geomorfológicos e físicos, uma vez que os estudos relacionados aos derramamentos de óleo neste tipo de meio era limitado. Os autores ressaltam a importância de diferenciar ambientes com vegetação herbácea, como as gramíneas, da vegetação lenhosa, como arbustos e árvores. Com algumas atualizações, os Estados Unidos utilizam esta classificação fluvial em seus manuais oficiais (NOAA, 2002, 2019), além de apresentarem índices próprios para regiões lacustres e estuarinas.

Uma distinta abordagem foi lançada em Hayes et al. (1995) contemplando a sensibilidade das bacias hidrográficas à montante dos grandes rios mapeados por índices fluviais, englobando pequenos rios e córregos. Este estudo foi continuado em Hayes et al. (1997) e aplicado em Porto Rico (Zengel et al., 2001).

A Environmental Protection Agency (EPA), agência de proteção ambiental dos Estados Unidos, em conjunto com algumas comissões de bacias hidrográficas desenvolveram um manual de referência para um Atlas de Sensibilidade Interior (EPA, 2000), que além de contemplar margens fluviais, integra essas informações com as dutovias, fontes potenciais de derramamentos, locais estratégicos para resposta nas regiões, entre outros fatores. A classificação da linha de costa é baseada no método utilizado pela NOAA, mas foi simplificada em quatro graus de sensibilidade: 1) Baixa sensibilidade (áreas urbanas ou desenvolvidas, costões rochosos, enrocamentos e barreiras de concreto); 2) Baixamédia sensibilidade (praias de areia e cascalho); 3) Média-alta sensibilidade (planícies de maré e bancos íngremes com vegetação baixa); e 4) Alta sensibilidade (mangues e pântanos).

No Brasil, ofoco principal dos mapeamentos 
também são as regiões costeiras e marinhas. Vários estudos desenvolveram adaptações dos métodos buscando melhor adequá-los ao litoral do país (Wieczorek et al., 2007; Cantagallo et al., 2008; Pincinato etal., 2009; Souza Filho etal., 2009; Andrade et al., 2010; Muler et al., 2011; Marinho \& Nicolodi, 2019). Alguns outros trabalhos foram desenvolvidos incorporando novos ambientes para a sensibilidade ao óleo como, por exemplo, o mapeamento em faixa de dutos (Mendes et al., 2005), o índice de sensibilidade ambiental terrestre (Martins et al., 2014) e a aplicação do Modelo Orientado à Representação do Pensamento Humano (MORPH) em uma análise específica de definição da sensibilidade para ambientes fluviais, desenvolvido por Costa et al. (2015).

O ambiente fluvial já foi alvo de estudo específico pela Petrobras (Petróleo Brasileiro S.A), que mapeou a sensibilidade da região amazônica e desenvolveu um ISL próprio (Araújo et al., 2006). Contudo, o ISL da região Amazônica não se aplica às demais regiões fluviais do Brasil em função de suas características peculiares de um ecossistema único e condições climáticas distintas de grande parte do país (Boulhosa \& Souza Filho, 2009; Souza Filho et al., 2009). No Rio Canhanduba (SC), Ferreira \& Beaumord (2008) aliaram Protocolos para Avaliação Rápida de Integridade de Rios e Riachos com uma adaptação das tabelas padrão de ISL do Ministério do Meio Ambiente, incluindo características físicas do corpo d'água, tais como correntes fluviais e profundidade média do trecho, além de características físicas das margens, como altura média.

Nesse contexto, o presente trabalho apresenta uma proposta metodológica para o desenvolvimento de um Índice de Sensibilidade ao Óleo em Ambientes Fluviais, aqui denominado de ISLF, tendo como aplicação a região do delta do Rio Jacuí, RS. Esta região abrange significativa movimentação portuária em função do terminal fluvial do polo petroquímico de Triunfo em uma área dealta sensibilidade ambiental que inclui ilhas e canais. A partir de uma classificação condizente com o ambiente, pretende-se contribuir com o arcabouço de informações necessárias para resposta a emergências, otimizando os esforços de limpeza e minimizando os impactos.

\section{2 Área, materiais e métodos}

O Delta do Rio Jacuí (Figura 1) é composto por 29 ilhas e áreas continentais, canais, pântanos e charcos, que se formam a partir do encontro dos rios Gravataí, Sinos, Caí e Jacuí, cujas águas, cujas águas formam o Lago Guaíba (Munhoz et al. 2017). Ele está localizado entre as bacias hidrográficas do Baixo Jacuí e do Lago Guaíba, na porção leste do estado do Rio Grande do Sul. O delta é composto de canais, baías rasas, ilhas fluviais e áreas continentais com banhados, florestas aluviais, várzeas e campos sujeitos a inundações periódicas. Algumas ilhas do delta possuem ocupação urbana e ribeirinha, além de atividade pesqueira. Está área está inserida na região metropolitana de Porto Alegre, capital estadual, sendo de grande importância econômica para o estado (MMA, 2016).

O delta está inserido na Planície Costeira do Rio Grande do Sul e é constituído principalmente por sedimentos quaternários do Holoceno, além de sedimentos terciários e rochas sedimentares pertencentes à bacia do Paraná e ao embasamento cristalino. A evolução da Planície Costeira indica que a área de estudo seria constituída por sedimentos associados aos depósitos lagunares pertencentes ao sistema de Barreiras Holocênicas e de retrabalhamento superficial do Sistema Laguna-Barreira III e do Sistema Laguna-Barreira IV (Tomazzelli \& Villwock, 2005).

O clima da região é o subtropical úmido com ventos predominantes de nordeste. As precipitações são mais acentuadas nas estações de outono e inverno, entre os meses de junho e setembro. Com a passagem de sistemas frontais, ventos intensos do quadrante sul causam represamento na descarga do Guaíba na Lagoa dos Patos. Estes eventos geram um aumento de nível no lago e algumas vezes até inversões de fluxos (Moller et al., 1996; Nicolodi et al., 2010). As flutuações do nível do delta estão relacionadas ao efeito do vento e aos períodos de maior ou menor descarga.

No ano de 1976 foi criado o Parque Estadual Delta do Jacuí (PEDJ), com o objetivo 


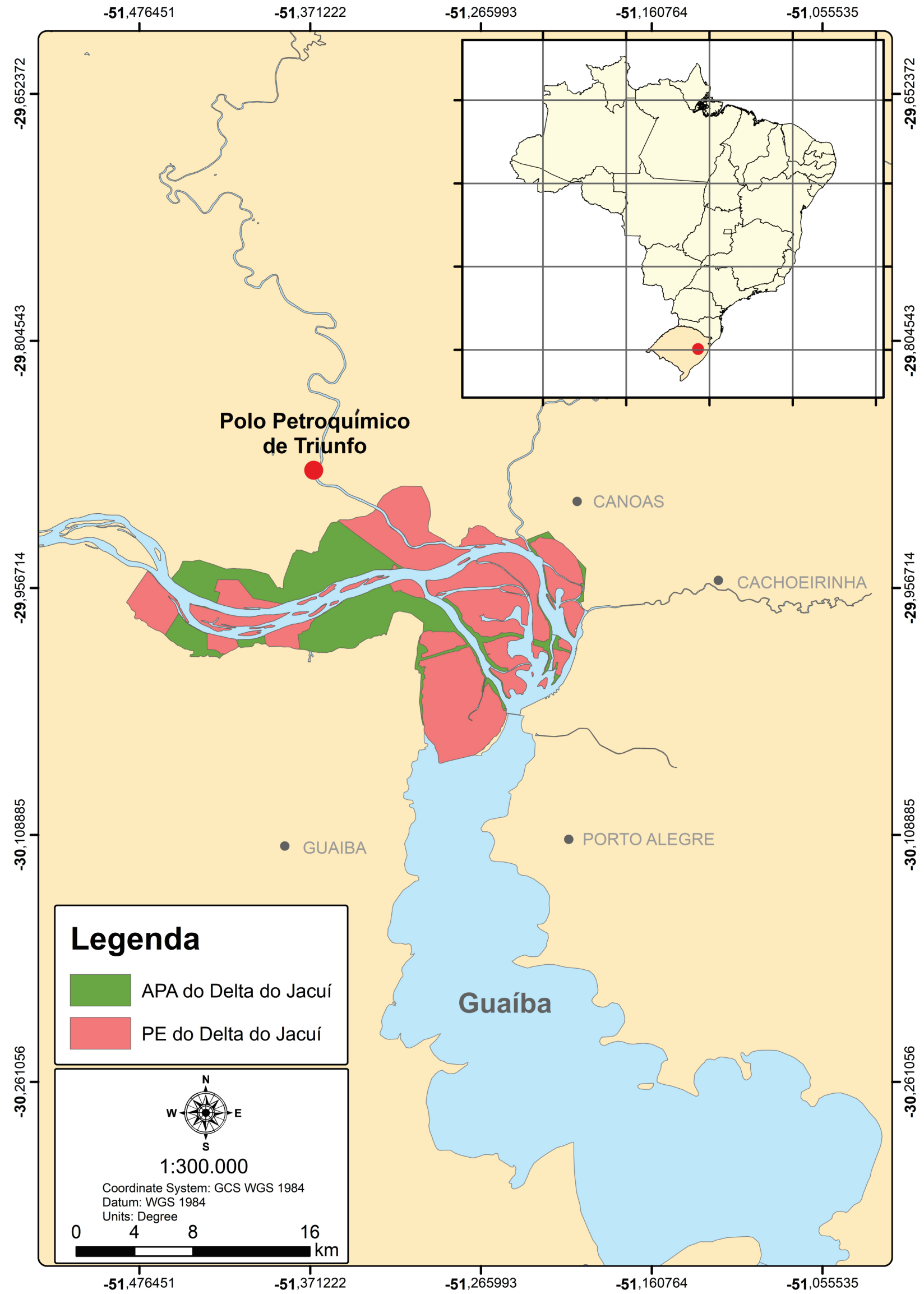

Figura 1. Mapa de localização do Delta do Rio Jacuí, Rio Grande do Sul. A área indicada em verde corresponde à Área de Preservação Ambiental do Delta do Jacuí e a área em rosa, o Parque Estadual do Delta do Jacuí.

Figure 1. Location map of the Delta do Rio Jacuí, Rio Grande do Sul. The área indicated in Green corresponds to the Enviromental Conservation Area of the Delta do Jacuí and the pink area of the Delta do Jacuí State Park. 
de preservar as ilhas do delta por seu valor cultural, ecológico e paisagístico, em meio a uma região densamente urbanizada. A região, desde 2005, também comporta a Área de Proteção Ambiental Estadual Delta do Jacuí (APAEDJ) nas áreas do entorno do parque. 0 parque abrange atualmente uma área de 14.242 ha e a APA 8.584 ha, englobando parte da região metropolitana de Porto Alegre (fig. 1).

Aimportância do PEDJ está na conservação de uma grande extensão de áreas úmidas e suas funções nos ciclos biogeoquímicos e hidrológicos, contribuindo para a manutenção da dinâmica hídrica do delta, amenizando as enchentes e as consequências da estiagem. Adicionalmente, a área desempenha um papel indispensável para inúmeras espécies da fauna, servindo como local de alimentação, abrigo, reprodução e berçário.

Apesar da importância ecológica, a região possui intenso tráfego diário de navios de óleo e derivados, que têm como destino o Polo Petroquímico de Triunfo. Este polo funciona desde a década de 70 e produz derivados como resinas termoplásticas, elastômeros, solventes, entre outros. A matéria prima para estes produtos chega principalmente através do terminal fluvial e de um duto vindo da refinaria Alberto Pasqualini (MMA, 2016). O Polo Petroquímico de Triunfo se comunica com o Rio Jacuí por meio de um canal artificial de 7,5 km de extensão. Conforme - Anuário Estatístico Aquaviário da Agência Nacional de Transportes Aquaviários (ANTAQ, 2019), o terminal trabalha com cargas do tipo granel líquido e carga geral solta, que chegam por meio de navegação de longo curso, cabotagem e interior. Atualmente, o terminal opera os seguintes produtos derivados de óleo: eteno, propeno, butadieno, benzeno, xileno, tolueno, etil benzeno, estireno, etanol, buteno-1, gasolina, entre outros hidrocarbonetos.

Para o desenvolvimento de uma classificação compatível com as características do ambiente fluvial, a metodologia de trabalho foi concebida em quatro etapas, as quais serão descritas a seguir: a) Estado da arte dos mapeamentos de sensibilidade ao óleo em ambiente fluvial; b) Sistematização das características do ambiente fluvial em estudo; c) Definição de critérios para classificação da sensibilidade dos ambientes; d) Aplicação dos critérios e Proposição de um índice de sensibilidade ao óleo para ambientes fluviais.

\subsection{Estado da arte dos mapeamentos de sensibilidade ao óleo em ambiente fluvial.}

Nesta etapa, foi realizada a sistematização das informações bibliográfıcas, possibilitando identificar metodologias para definição de sensibilidade ao óleo empregadas em regiões costeiras e fluviais, tanto no Brasil quanto em outros países. A busca foi realizada por meio do portal de periódicos da Coordenação de Aperfeiçoamento de Pessoal de Nível Superior - CAPES com as plataformas Science Direct, BioOne e Web Of Science além do Google e do Google acadêmico. A procura por requisitos legais de outros países foi feita por meio do Google. Ambas as buscas utilizaram palavraschave sobre o tema em inglês e português.

A partir dos resultados desta análise e tendo como base a metodologia da NOAA (2002, 2019), a qual subsidiou o desenvolvimento do escopo metodológico utilizado no Brasil, a presente pesquisa considerou os diferentes tipos de vegetação encontrados nas margens de rios, incluindo parâmetros como altura, composição e densidade das espécies. Adicionalmente, as feições geomorfológicas auxiliaram na determinação da sensibilidade do litoral, como a presença ou não de barrancos formados pelas diferenças de nível. Alguns outros trabalhos apontaram fatores secundários para o índice desenvolvido, como Hayes et al. (1997), que incluiu a acessibilidade para contingência, o fluxo do rio e a presença córregos como importantes fatores para a classificação da sensibilidade das margens. Algumas classes utilizadas na metodologia oficial do MMA (2007) foram adaptadas para a realidade do ambiente fluvial.

\subsection{Sistematização das características do ambiente fluvial}

Esta etapa consistiu no levantamento de dados da região do Delta do Rio Jacuí e do Polo Petroquímico de Triunfo. A busca por trabalhos publicados sobre a região foi realizada de modo 
semelhante à primeira etapa, utilizando o portal de periódicos da CAPES e o Google.

Foram realizados dois trabalhos de campo (junho de 2013 e agosto de 2014) para aquisição de dados quanto à geomorfologia e hidrodinâmica da região, seguindo a metodologia proposta por MMA (2007), e posterior mapeamento de sensibilidade ao óleo. Para facilitar o reconhecimento no campo, uma préclassificação do ambiente foi elaborada a partir da análise semântica de imagens de satélite disponíveis no software Google Earth Pro, com uma resolução espacial de aproximadamente 1 m (obtidas com a maior resolução disponível - 4800 x 2255 pixels). Os trabalhos de campo foram executados a bordo de uma embarcação pesqueira viabilizada no âmbito do projeto "Mapeamento de Sensibilidade ao óleo da Bacia de Pelotas" e incluiu registros fotográficos georreferenciados e classificação das margens, além do levantamento das suas características, já preconizado na metodologia de MMA (2007). Durante estes embarques, foi observado que a vegetação presente nas margens poderia ser distribuída em quatro grupos distintos, os quais foram utilizados na adaptação metodológica de definição do ISLF, conforme será demonstrado no capítulo de resultados. Cabe ressaltar que uma das variáveis mais importantes para a definição do ISL da região é o nível das águas, principalmente em função de questões relacionadas à precipitação na bacia hidrográfica. Os levantamentos em campo foram realizados em duas situações distintas, sendo a primeira em uma situação de normalidade (dentro da média) e a segunda em uma condição de nível acima da média. Os dados utilizados serão apresentados no tópico de resultados e são oriundos de medição oficial do governo do RS (GADEC, 2014).

\subsection{Definição de critérios para classificação da sensibilidade dos ambientes}

Nesta etapa, foram analisados os parâmetros referentes à sensibilidade ambiental, espécies com maior ou menor grau de sensibilidade ao óleo e nível de dificuldade para contenção e remoção do produto, seguindo as diretrizes metodológicas de NOOA (2002;
2019) e MMA (2007). Esta etapa compreendeu, ainda, de revisão bibliográfica e de aplicação da metodologia de elicitação de informação, aqui compreendida como uma técnica de obtenção de dados junto a especialistas detentores de informações visando à concepção de conceitos (Martin et al. 2012; Krueger et al. 2012; Ban et al. 2015). Tal aplicação buscou a proposição de uma adaptação à classificação já existente para ambientes costeiros que venha a possibilitar o ordenamento dos ambientes com maior ou menor sensibilidade para ambientes fluviais e deltaicos. Para tanto, o Plano de Manejo do Parque Estadual do Delta do Jacuí, elaborado pela Fundação Zoobotânica do Rio Grande do Sul (FZB, 2014), foi uma ferramenta importante e que complementou as informações utilizadas nos trabalhos de campo, principalmente a partir de do mapa de uso e cobertura do solo e das descrições e classificações das espécies vegetais ali presentes.

\subsection{Aplicação dos critérios e Proposição de um índice de sensibilidade ao óleo para ambientes fluviais.}

Esta etapa consolidou o Índice de Sensibilidade do Litoral Fluvial (ISLF). Nesse ponto foi montada a escala hierárquica das classes de ISLF para a região de estudo, definindo o tipo de margem, descrevendo as características do ambiente e o comportamento potencial do óleo. O ISLF foi embasado nas classificações propostas pela NOAA $(2002 ; 2019)$ e pelo MMA (2007), numa escala de 1 a 10 de sensibilidade crescente, facilitando assim a comparação e aplicação do método.

Os índices foram elaborados levando em consideração os processos físicos ativos e a geomorfologia dos rios, como salienta Hayes et al. (1995). Os mapeamentos realizados pela NOAA $(2004,2006)$ ressaltam que os critérios como tipo de substrato e declividade da margem são imprescindíveis para prever como o óleo irá impactar o ambiente, já que afetam a permeabilidade e o tempo de permanência do poluente. A diferenciação das características de derramamentos de óleo apresentado em Baca et al. (1985) para ambientes de água doce de alta ou 
baixa energia ajudou na defınição dos ambientes com maior sensibilidade.

A vegetação encontrada no Delta do Rio Jacuí foi uma variável determinante, uma vez que Oliveira (2007) identificou sua interação com os processos de sedimentação deltaica, sendo as matas aluviais encontradas sobre os diques marginais e os banhados localizados nas planícies de inundação e depósitos de calha da rede fluvial. Estas informações permitem inferir no alcance e permeabilidade que o óleo terá nas feições fluviais. Outro ponto importante em relação ao tipo de vegetação associada às margens é que as plantas herbáceas e arbustivas são mais sensíveis ao óleo que a vegetação de porte lenhoso (Baca et al., 1985; Hayes et al.,1995).

Como resultado final, a adaptação metodológica proposta por meio da criação do ISLF foi aplicada em toda a região do Delta do Jacuí, gerando um conjunto de cinco cartas operacionais em escala 1:25000, as quais encontram-se no apêndice deste artigo.

\section{Resultados e discussão}

As principais variáveis consideradas na composição do índice foram tipo de substrato, declividade e tipo da margem e tipo de vegetação associada (composição da margem vegetada), já que estas interferem diretamente no comportamento do óleo quando este tocar a margem do rio. Em linhas gerais, pode-se dizer que a sensibilidade do ambiente aumenta conforme cresce a produtividade biológica e diminui a declividade.

Uma variável importante neste contexto é a energia do fluxo da água, uma vez que a mesma irá atuar no potencial de remoção natural do óleo. Ainda que Tsahalis (1979) e Baca et al. (1983) demonstrem o comportamento do óleo em rios meandrantes e o potencial de concentração do óleo em determinadas regiões em virtude dos meandramentos, esta variável não compõe, de forma direta, os índices de sensibilidade analisados.

Os índices oficiais dos Estados Unidos (NOAA, 2002; 2019) e Brasil (MMA, 2007) também utilizam o grau de exposição à energia de ondas e marés, além da declividade da margem e o tipo do substrato, como variáveis para compor o índice de sensibilidade. A classificação da NOAA adiciona o fator "Sensibilidade e Produtividade Biológica" como determinante para os índices propostos. Os ambientes vegetados, como marismas, banhados e manguezais, possuem as maiores sensibilidades devido aos potenciais impactos de longo prazo resultantes tanto da exposição ao óleo quanto dos danos associados às atividades de limpeza destes habitat (NOAA, 2002, 2019).

Nas cartas desenvolvidas pela NOAA como a do Rio Hudson (NOAA, 2006) e Rio Columbia (NOAA, 2004) foram elencados os fatores já mencionados, mas também a facilidade de limpeza como uma variável importante para integrar a sensibilidade do ambiente. A limpeza do ambiente está relacionada ao tempo que o óleo permanecerá impactando o ambiente, além do possível soterramento do produto durante os procedimentos de limpeza.

O tipo de vegetação influencia na forma como o óleo vai penetrar nos sedimentos e também no grau de dificuldade de contenção e remoção, uma vez que diferentes espécies de plantas cobrem as margens. Em sistemas deltaicos, ou rios de planície, a ocorrência de distintos habitat aquáticos e transicionais propicia a manutenção de uma considerável biodiversidade (Thomaz et al., 1997). A vegetação do Delta do Jacuí é dividida em dois tipos de ambientes naturais: florestas e banhados. Nas margens, os dois grupos são encontrados, mas os banhados cobrem as maiores áreas. Adicionalmente, os banhados são mais sensíveis ao óleo pela estrutura e porte das plantas e ainda pela importância ecológica como berçários e fontes de alimentos para a fauna local.

O tipo do substrato determina a permeabilidade e mobilidade do sedimento, características estas que formam a estrutura básica determinante das comunidades biológicas que venham a existir em determinado local. Substratos permeáveis tendem a um maior tempo de permanência, uma vez que a penetração do óleo é maior. A mobilidade do sedimento pode diminuir a permanência do óleo ou, ao contrário, incorporá-lo aos estratos 
sedimentares inferiores (MMA, 2007).

A declividade está relacionada ao alcance que o óleo terá ao chegar à margem: ambientes mais planos como praias ou bancos vegetados tendem a uma maior área afetada do que escarpas e estruturas artificiais, associadas a uma maior declividade. Em ambientes expostos, a declividade influencia diretamente na reflexão e quebra das ondas, determinando assim, o tempo de permanência do óleo e a capacidade de limpeza natural do local atingido. Segundo NOAA (2002; 2019), em ambientes protegidos, a declividade é uma variável menos importante para o impacto do óleo, exceto quando as comunidades biológicas possuem maior área para se desenvolverem, como é, especificamente, o caso do delta do Rio Jacuí.

Uma das variáveis que terá maior influência na sensibilidade dos ambientes é o nível d'água no momento do incidente. Em níveis mais elevados a tendência é que o óleo atinja áreas adjacentes às margens, muitas vezes compostas por ambientes onde o comportamento do óleo é mais complexo, dificultando a contenção e limpeza. Há uma tendência de aumento do ISLF nesse tipo de situação, uma vez que praias, escarpas, muros e demais tipos de margens podem estar submersas e o óleo atingir diretamente os diversos tipos de vegetação existentes. Um parâmetro que é relacionado diretamente ao nível d’água é a declividade do substrato, já que quanto menor for a inclinação da margem, maior será o alcance horizontal do óleo.

Os ambientes deltaicos são influenciados diretamente pela descarga dos rios que os formam. Além da descarga, outro fator importante para o Delta do Rio Jacuí é o efeito do vento empilhando a água do Guaíba, ocasionando um aumento do nível das águas no local (Nicolodi et al., 2010). Normalmente os maiores níveis do Guaíba ocorrem nos meses de junho a outubro, condicionados pela alta precipitação nas bacias hidrográficas.

A variável 'nível d'água' foi analisada em dois embarques utilizados para o mapeamento: o primeiro deles ocorreu com o nível de 0,78m, segundo medição oficial do governo do Rio Grande do Sul. Este pode ser considerado um nível normal, levando em conta as suas médias históricas (GADEC, 2014). Já no segundo embarque, o cenário era de elevação do nível do rio com o registro de $1,44 \mathrm{~m}$, alterando consideravelmente o cenário da classificação anterior.

O fluxo do rio também é um fator importante, pois interfere na dinâmica da mancha de óleo. Se o fluxo for intenso, irá espargir a mancha à jusante espalhando a contaminação. Por outro lado, se a energia for baixa, o óleo permanecerá mais tempo impactando o local. A hidrodinâmica do ambiente fluvial também afeta a capacidade de autodepuração e a persistência do óleo no ambiente. Na resposta à emergência, baixos fluxos auxiliam a contenção e retirada do óleo do ambiente. Esta é uma das características do local mapeado, um ambiente deltaico, onde se percebe uma tendência de diminuição do fluxo do rio, o que favorece a sedimentação do material carreado, formando ilhas e canais característicos destes ambientes (Gurnell et al., 2012).

Nos canais do interior do delta, a sensibilidade tende a ser mais elevada dada a presença constante de vegetação nas margens. Contribui para este cenário o fato de que, em algumas situações, os canais secundários mais estreitos possuem fluxo de água menos intenso quando comparados aos canais principais. Esta variável é dinâmica e depende da época do ano e do regime de chuvas, sendo que, em condições específicas, os canais secundários e afluentes conseguem ter velocidades superiores ao rio principal, notadamente em períodos de menor pluviosidade (Zancan Filho \& Quadros, 2017). Ainda que esta variável tenha sido identificada, ela não é um fator componente do índice proposto, uma vez que essa variação do fluxo do rio não é uma característica homogênea na área estudada. Este fator não impede que tais considerações sejam apontadas em recomendações e diretrizes específicas para ações de resposta aos incidentes com óleo.

Para facilitar a compreensão e permitir uma comparação, o índice desenvolvido segue - mesmo principio do adotado pelo MMA (2007), com ISL crescendo conforme o grau de sensibilidade. Como a região de estudo não possui tantos ambientes distintos optou-se por não seguir o padrão da NOAA (2019) que 
hierarquiza as classes do índice com letras (exemplo: A, B, C, etc.). Assim, cada ambiente foi definido com um ISLF de 1 a 10.

A classificação criada foi denominada Índice de Sensibilidade ao Litoral Fluvial (ISLF) e encontra-se na Tabela 1. Esta tabela foi organizada conforme o modelo apresentado no Manual do MMA (2007), sendo que o grau de exposição às ondas foi suprimido e adaptou-se o parâmetro faixa intermarés por declividade, já que se trata de um ambiente fluvial.

Com base no arcabouço técnico e conceitual discutido anteriormente foram elaboradas cinco cartas operacionais, sendo uma em escala 1:50.000 (fig. 2) e outras quatro em escala 1:25.000 para a região do Delta do Jacuí, disponíveis nas Figuras 3, 4, 5 e 6.

Como forma de subsidiar o mapeamento de sensibilidade ao óleo em ambientes fluviais e deltaicos, as figuras 7 e 8 descrevem as principais características dos índices (ISFL) elaborados para a região do Delta do Jacuí a partir das classes descritas na Tabela 1.

Cabe ressaltar uma importante característica do ambiente estudado: a relação entre a variação de nível d'água, influenciada pela descarga dos rios e efeito do vento, e a permeabilidade do substrato. Diversos autores apontam que, em períodos de outono e inverno, a frequência da passagem de sistemas frontais do quadrante sul aumenta, assim como aumenta a intensidade e frequência dos ventos de mesma orientação (Castelão \& Möller, 2003; Nicolodi et al. 2010; Scottá et al. 2019). Este fator é relevante em ambientes onde os substratos possuem baixos graus de seleção, como é o caso das margens lagunares do Guaíba e Delta do Jacuí.

Essa disposição não é estática, como

Tabela 1. Tabela de Índice de Sensibilidade do Litoral Fluvial (ISLF) com os principais parâmetros adotados na classificação.

Table 1. Table of the Fluvial Coastal Sensitivity Index (ISLF) with the main parameters adopted in this classification.

\begin{tabular}{|c|c|c|c|c|}
\hline \multirow{2}{*}{$\begin{array}{c}\text { Índice de } \\
\text { Sensibilidade } \\
\text { Litoral } \\
\text { (ISLF) }\end{array}$} & \multirow[t]{2}{*}{ Tipo de Litoral } & \multirow[t]{2}{*}{ Declividade } & \multicolumn{2}{|c|}{ Substrato } \\
\hline & & & Tipo & $\begin{array}{c}\text { Penetração do } \\
\text { óleo }\end{array}$ \\
\hline 1 & $\begin{array}{c}\text { Muros / Estruturas } \\
\text { Verticais }\end{array}$ & Alta & $\begin{array}{l}\text { Estrutura } \\
\text { Artificial }\end{array}$ & Impermeável \\
\hline 2 & $\begin{array}{c}\text { Substrato de } \\
\text { Declividade Média / } \\
\text { Estruturas de Madeiras }\end{array}$ & Moderada & $\begin{array}{l}\text { Estrutura } \\
\text { Artificial }\end{array}$ & Impermeável \\
\hline 3 & Escarpas & Moderada/Alta & Areia & Semipermeável \\
\hline 4 & $\begin{array}{c}\text { Praia Areia Média / } \\
\text { Fina }\end{array}$ & Baixa & Areia & Semipermeável \\
\hline 5 & $\begin{array}{c}\text { Praia Mista / Areia } \\
\text { Grossa }\end{array}$ & Moderada & $\begin{array}{l}\text { Areia, Substrato } \\
\text { Rochoso }\end{array}$ & Permeável \\
\hline 6 & Entulhos e Resíduos & Moderada & $\begin{array}{l}\text { Areia, Cascalho, } \\
\text { Entulho }\end{array}$ & Permeável \\
\hline 7 & Escarpas Vegetadas & Moderada & $\begin{array}{l}\text { Areia, substrato } \\
\text { rochoso }\end{array}$ & $\begin{array}{l}\text { Penetração } \\
\text { limitada }\end{array}$ \\
\hline 8 & Bancos Vegetados & Baixa & Areia Lamosa & $\begin{array}{l}\text { Penetração } \\
\text { limitada }\end{array}$ \\
\hline 9 & Florestas & Moderada & $\begin{array}{c}\text { Detritos de } \\
\text { origem aluvial }\end{array}$ & $\begin{array}{c}\text { Permeável / } \\
\text { baixa } \\
\text { permeabilidade }\end{array}$ \\
\hline 10 & $\begin{array}{c}\text { Banhados / Macrófitas } \\
\text { de Margem }\end{array}$ & Baixa & Lamoso & $\begin{array}{c}\text { Baixa } \\
\text { permeabilidade }\end{array}$ \\
\hline
\end{tabular}


a metodologia oficial brasileira (MMA, 2007) considera, mas varia de acordo com os níveis de energia atuantes no momento. Dessa forma, a permeabilidade dos ambientes, crucial para o comportamento do óleo, varia também de acordo com o nível hídrico presente e com a intensidade e direção dos ventos atuantes, levando a uma variação também da sensibilidade ambiental. Essas considerações também são apresentadas por Oliveira \& Nicolodi (2016), no qual os autores demonstraram - através de testes de permeabilidade com óleo cru - em amostras do sistema lagunar Patos-Guaíba a existência de correlação entre a permeabilidade dos ambientes e a constituição polimodal dos pacotes sedimentares e suas variações na distribuição espacial das partículas em condições energéticas distintas.

Esta característica complexidade ao mapeamento, uma vez que algumas margens podem mudar sua sensibilidade ao óleo conforme o nível do rio. Quando comparados os dois mapeamentos realizados com nível d'água distinto, é possível identificar pontos ao longo do Delta do Jacuí nos quais houve essa mudança na classificação do ISLF. Tal situação deve ser considerada na realização de mapeamentos deste tipo, podendo o mesmo prever dois ISFL distintos (ISLF dinâmico) para a mesma região, em função do nível das águas. As Cartas SAO são, em sua concepção, instrumentos estáticos, o que dificulta a inclusão de variáveis dinâmicas na classificação de sensibilidade ambiental. Além das classes específicas para ambientes fluviais propostas neste trabalho, variações de abordagem do método podem ser necessárias, considerando principalmente, as características dinâmicas do meio, como vazão, nível dos rios e direção dos ventos.

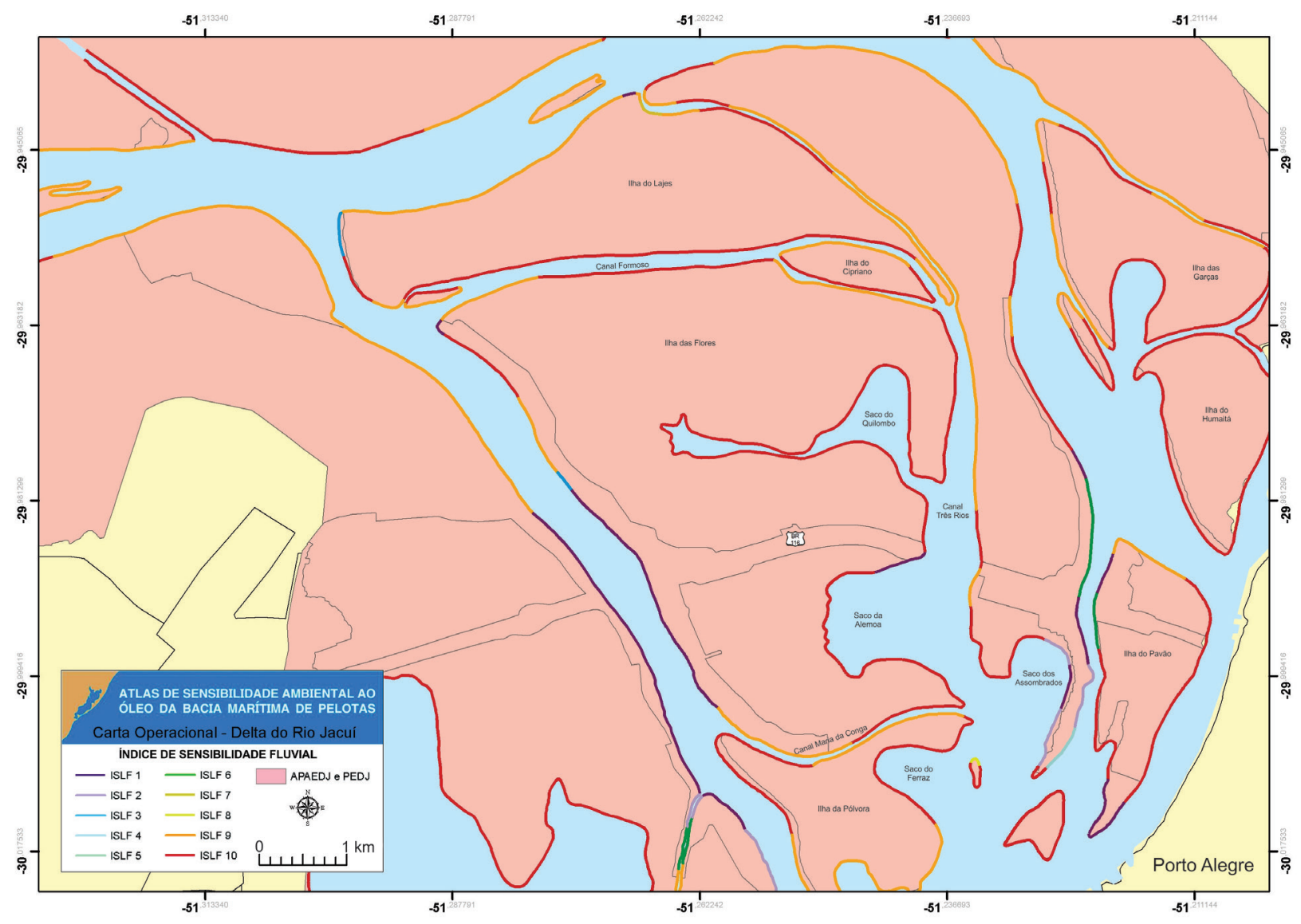

Figura 2. Carta operacional "Delta do Rio Jacuí" em escala 1:50000 da região do Delta do Jacuí com o mapeamento de Sensibilidade ao óleo adaptada para ambientes fluviais (ISLF).

Figure 2. Operational chart "Delta do Rio Jacuí" in scale 1: 50000 of the region of Delta do Jacuí, with the mapping of Oil Sensitivity adapted for fluvial environments (ISLF). 


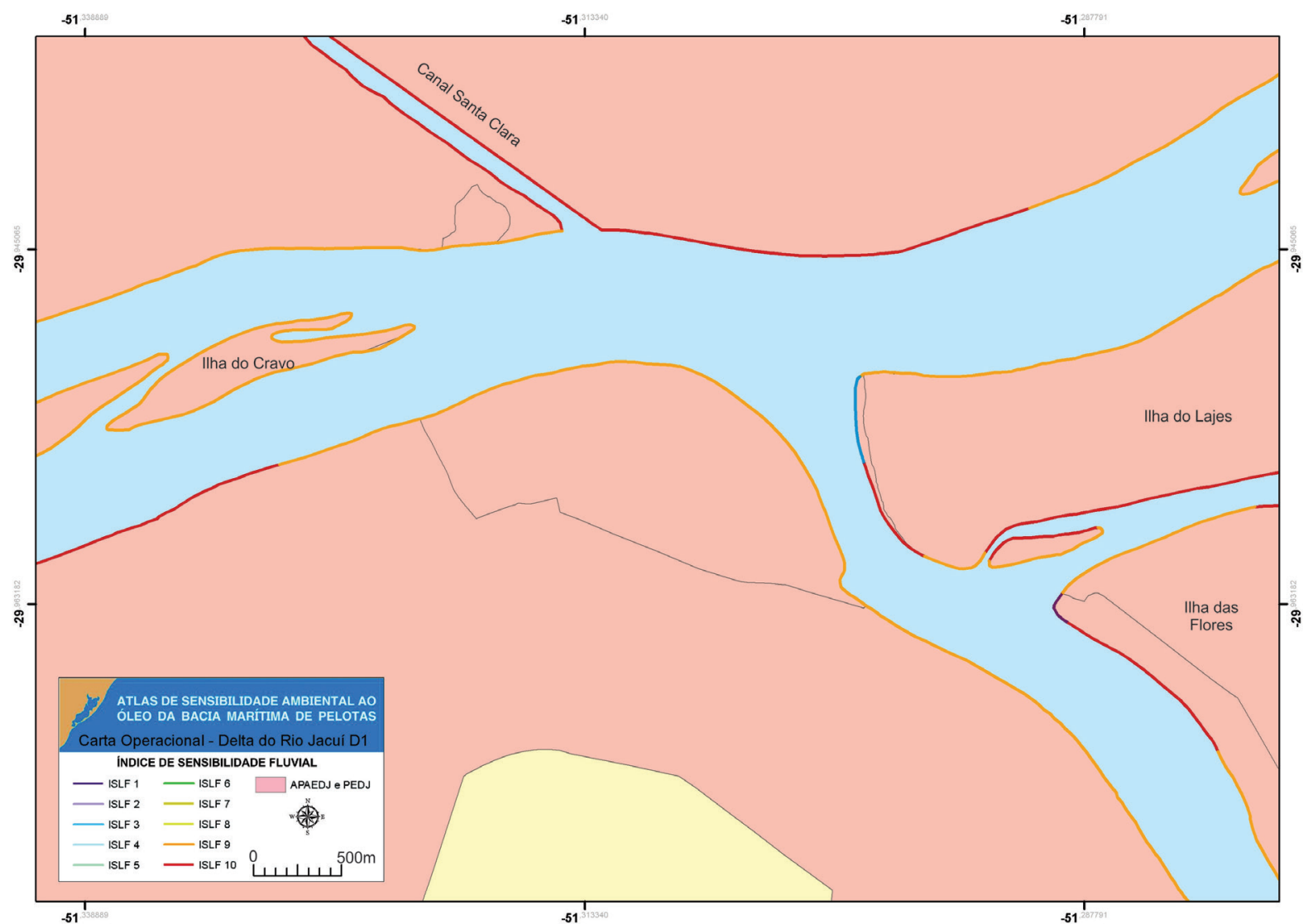

Figura 3. Carta operacional "Delta do Rio Jacuí - D1" em escala 1:25000 da região do Delta do Jacuí com o mapeamento de Sensibilidade ao óleo adaptada para ambientes fluviais (ISLF).

Figure 3. Operational chart "Delta do Rio Jacuí - D1" in scale 1: 25000 of the region of Delta do Jacuí with the mapping of Oil Sensitivity adapted for fluvial environments (ISLF).

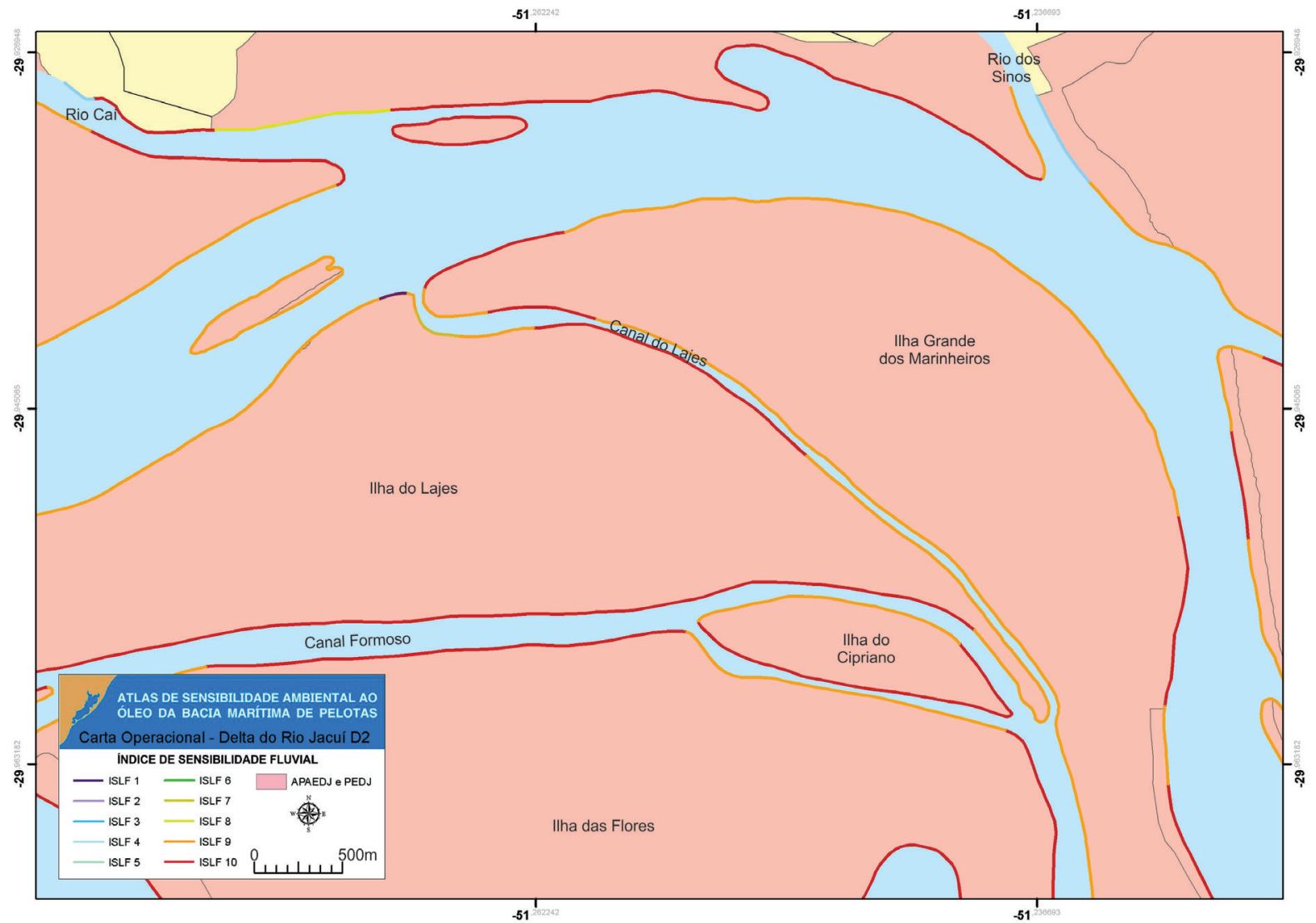

Figura 4. Carta operacional "Delta do Rio Jacuí - D2" em escala 1:25000 da região do Delta do Jacuí com o mapeamento de Sensibilidade ao óleo adaptada para ambientes fluviais (ISLF).

Figure 4. Operational chart "Delta do Rio Jacuí - D2" in scale 1: 25000 of the region of Delta do Jacuí with the mapping of Oil Sensitivity adapted for fluvial environments (ISLF). 


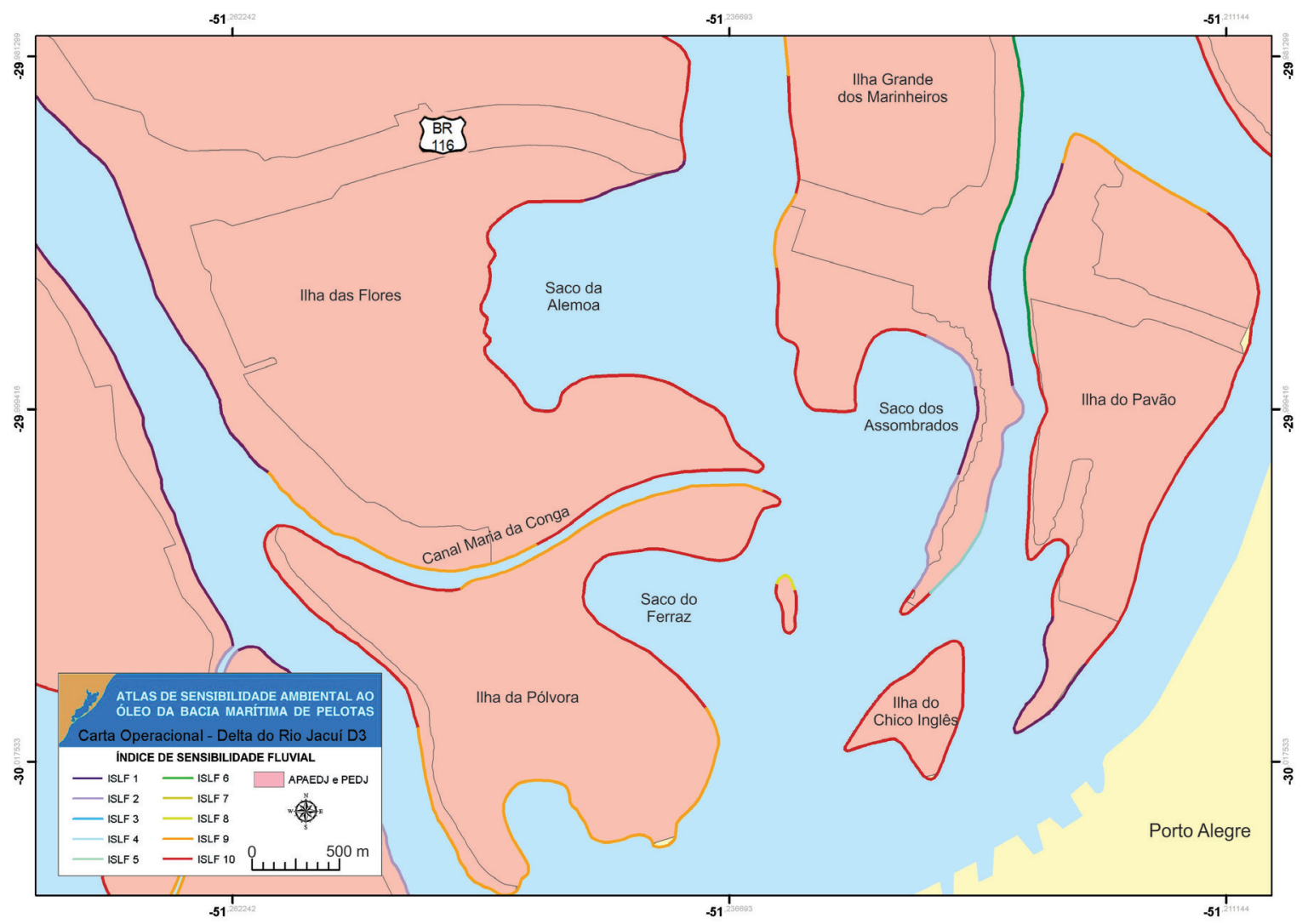

Figura 5. Carta operacional "Delta do Rio Jacuí - D3" em escala 1:25000 da região do Delta do Jacuí com o mapeamento de Sensibilidade ao óleo adaptada para ambientes fluviais (ISLF).

Figure 5. Operational chart "Delta do Rio Jacuí - D3" in scale 1: 25000 of the region of Delta do Jacuí with the mapping of Oil Sensitivity adapted for fluvial environments (ISLF).

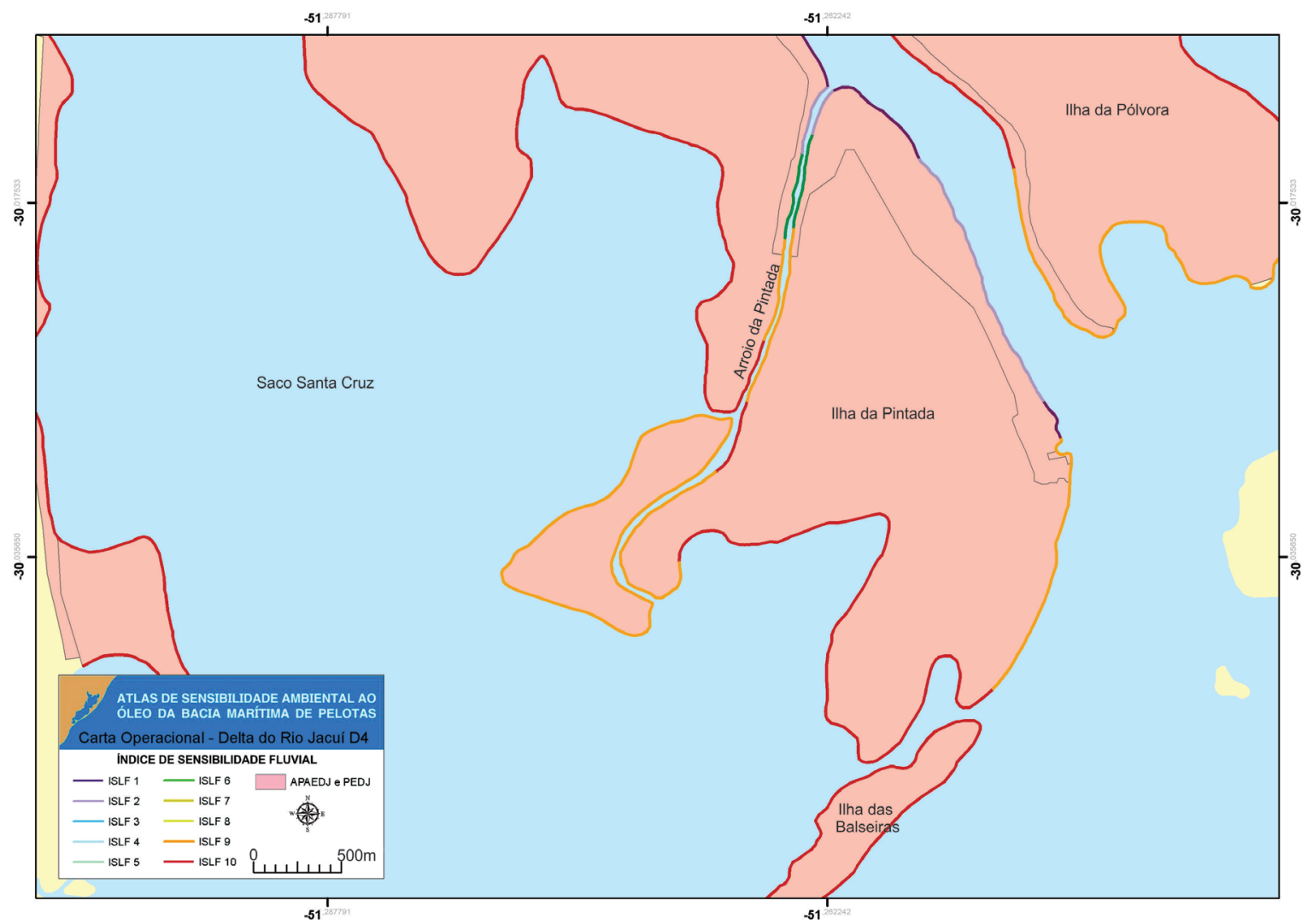

Figura 6. Carta operacional "Delta do Rio Jacuí - D4" em escala 1:25000 da região do Delta do Jacuí com o mapeamento de Sensibilidade ao óleo adaptada para ambientes fluviais (ISLF).

Figure 6. Operational chart "Delta do Rio Jacuí - D4" in scale 1: 25000 of the region of Delta do Jacuí with the mapping of Oil Sensitivity adapted for fluvial environments (ISLF). 


\begin{tabular}{|c|c|c|}
\hline $\begin{array}{l}\text { Índice de Sensibilidade } \\
\text { Litoral Fluvial (ISLF) }\end{array}$ & Descrição & Exemplo \\
\hline $\begin{array}{l}\text { 1. Muros / } \\
\text { Estrutura Verticais }\end{array}$ & $\begin{array}{l}\text { Apresenta substrato impermeável com declividade alta, além de } \\
\text { estrutura artificial. Normalmente em ambiente urbanizado, não } \\
\text { possui comunidades biológicas nas margens, tendo baixa } \\
\text { importância ecológica. Neste tipo de ambiente não há penetração do } \\
\text { óleo, portanto há baixa permanência. Apesar de não ser um } \\
\text { ambiente exposto como classifica NOAA e MMA, este é o tipo de } \\
\text { litoral menos permeável pela estrutura e declividade (maior que } 30 \\
\text { graus). }\end{array}$ & W \\
\hline $\begin{array}{l}\text { 2. Substrato de declividade } \\
\text { Média/Estruturas de } \\
\text { Madeira }\end{array}$ & $\begin{array}{l}\text { Engloba ambientes diversos com substrato impermeável, não vertical } \\
\text { (declividade moderada) e estrutura artificial, incluindo estruturas de } \\
\text { madeira. Difere do ISLF } 1 \text { em função da menor declividade, o que } \\
\text { possibilita maior área de alcance do óleo em casos de rio com nível } \\
\text { alto. Como no ISLF } 1 \text {, neste ambiente não ocorre penetração } \\
\text { significativa do óleo. Em ambientes como estes (declividade entre } 5^{\circ} \\
\text { até } 30^{\circ} \text { ), caso o nível do rio esteja elevado o óleo pode se depositar } \\
\text { ou acumular na faixa superior sendo importante sua remoção. }\end{array}$ & 7. \\
\hline 3. Escarpas & $\begin{array}{l}\text { Presença de substrato de areia, semipermeável com declividade } \\
\text { moderada a alta. Nestes substratos já existe certa permeabilidade do } \\
\text { óleo, mas a inclinação não permite que este alcance áreas além das } \\
\text { margens. Margens com escarpas são bem características de rios com } \\
\text { alto fluxo. Esta categoria engloba escarpas, encostas íngremes e } \\
\text { bancos de sedimentos inconsolidados expostos. Os sedimentos são } \\
\text { bem selecionados e compactados, com penetração do óleo geralmente } \\
\text { menor que } 10 \mathrm{~cm} \text {. }\end{array}$ & \\
\hline $\begin{array}{l}\text { 4. Praia Areia Média/ } \\
\text { Fina }\end{array}$ & $\begin{array}{l}\text { Tem como base a classificação do MMA para praias abrigadas, com } \\
\text { substrato de areia média e fina, semipermeáveis e com declividade } \\
\text { baixa }\left(<\text { que } 5^{\circ}\right) \text {. As características do comportamento do óleo são } \\
\text { semelhantes ao ISLF 3: sedimentos selecionados e com penetração } \\
\text { menor que } 10 \mathrm{~cm} \text {. A menor declividade possibilita uma maior área } \\
\text { para alcance do óleo e impacto no local. } \\
\text { Praias que apresentam largura reduzida podem apresentar inundação } \\
\text { total, ficando o ambiente ficar submerso em casos de alto nível do rio, } \\
\text { neste cenário a classificação do ISLF pode ser alterada. }\end{array}$ & 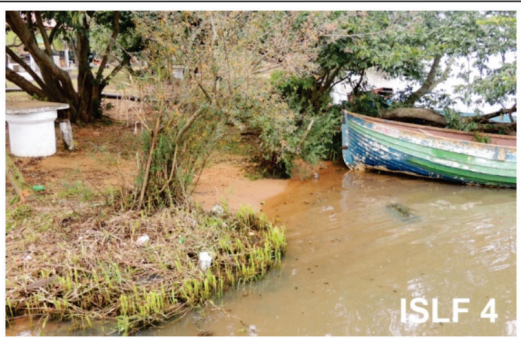 \\
\hline $\begin{array}{l}\text { 5. Praias Mistas e de } \\
\text { Areia Grossa }\end{array}$ & $\begin{array}{l}\text { Praias mistas e de areia grossa com declividade moderada, } \\
\text { permeáveis e que apresentam como tipo de substrato areia ou } \\
\text { substrato rochoso. Praias de areia grossa são características de } \\
\text { ambientes fluviais, mas não tanto de ambientes deltaicos porque com } \\
\text { a diminuição da competência a areia grossa deposita e não é mais } \\
\text { transporta para estes ambientes. Apresentam uma maior penetração } \\
\text { do que as praias de areia média, até cerca de } 25 \mathrm{~cm} \text { de profundidade. } \\
\text { A mobilidade destes sedimentos pode causar soterramento e a maior } \\
\text { percolação do óleo dificultar a limpeza. }\end{array}$ & inge. \\
\hline
\end{tabular}

Figura 7. Descrição das cinco primeiras classes do Índice de Sensibilidade Litoral Fluvial (ISLF), com base no estudo de caso do Delta do Rio Jacuí, RS.

Figure 7. Description of the first five categories of Fluvial Coastal Sensitivity Index (ISLF), based on the case study of the Delta do Rio Jacuí, RS 


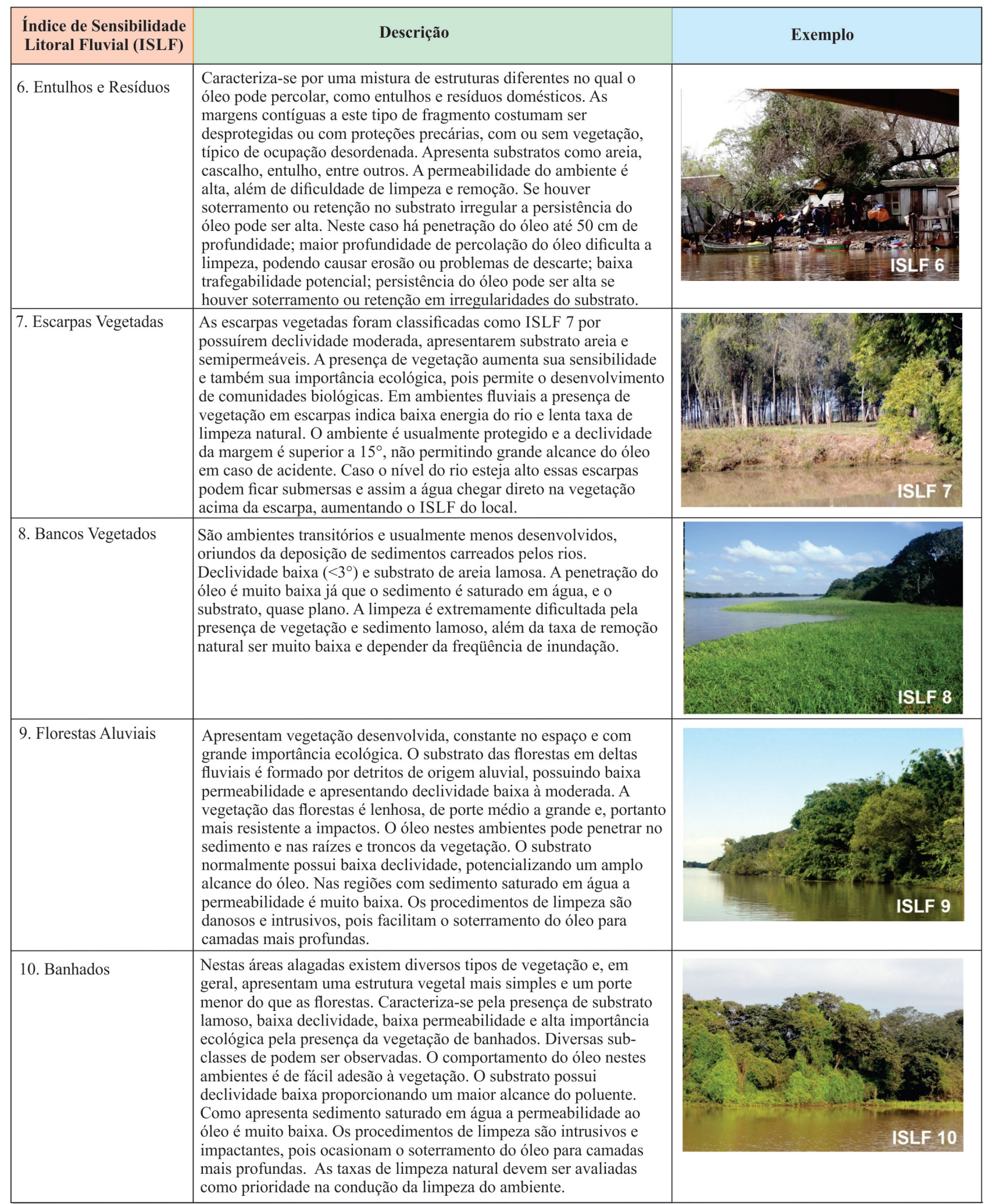

Figura 8. Descrição das cinco últimas classes do Índice de Sensibilidade Litoral Fluvial (ISLF), com base no estudo de caso do Delta do Rio Jacuí, RS.

Figure 8. Description of the last five categories of Fluvial Coastal Sensitivity Index (ISLF), based on the case study of the Delta do Rio Jacuí, RS. 
Por sua vez, a distinção das categorias de margens vegetadas seguiu as diferenças de declividade, substrato e tipo de vegetação associada encontrados nas mesmas. A importância ecológica, transitoriedade (ou não) do ambiente e características específicas de cada tipo de vegetação (porte e capacidade de regeneração) permitiram desenvolver as categorias de ISLF. A presença de vegetação eleva a sensibilidade das regiões, devendo a proteção com barreiras ser prioritária para que as manchas de óleo não alcancem estes ambientes.

$\mathrm{O}$ índice aqui proposto julga contemplar a diversidade e complexidade que os ambientes fluvio-deltaicos apresentam, esperando contribuir à discussão acerca do aperfeiçoamento metodológico do mapeamento de sensibilidade ao óleo.

\section{Conclusões}

O presente trabalho propôs o desenvolvimento do Índice de Sensibilidade do Litoral em ambientes Fluviais (ISLF), tendo como base o estudo realizado na região do Delta do Rio Jacuí, RS. O ISLF é uma adaptação metodológica do Índice de Sensibilidade do Litoral (ISL) e é composto por 10 classes de ambientes encontrados nas margens da área de estudo, as quais foram apresentadas na ordem crescente de sensibilidade a derramamentos de óleo.

Esta adaptação metodológica levou em consideração, além das variáveis já normalmente aplicadas na metodologia de definição do ISL, alguns aspectos que não são contemplados no método tradicional de definição de sensibilidade utilizado no Brasil, com destaque para o nível d'água e presença ou ausência de vegetação associada à margem. Adaptações como estas favorecem a utilização desse tipo de informação, normalmente inserida no contexto das Cartas de Sensibilidade ao Óleo (CARTAS SAO), em cenários de crise, onde uma resposta embasada em critérios técnicos condizentes com os ambientes a serem atendidos é ponto crucial para a sua efetividade.

Este trabalho buscou contribuir na discussão acerca do aperfeiçoamento dos métodos e instrumentos utilizados em ações de contingência aos incidentes com óleo no país, trazendo novas perspectivas para a sensibilidade fluvial e motivando outros esforços nesta temática, visto que há poucas informações sobre o impacto do óleo nas margens fluviais e tipos de vegetação associadas. Considera-se aqui que a inclusão de variáveis dinâmicas poderia ser uma alternativa futura para aperfeiçoar a resposta às emergências neste tipo de ambiente. Esperase que este estudo incite complementações e atualizações nas metodologias usuais para a classificação de linhas de costa que venham a subsidiar avanços nessa temática, principalmente no que diz respeito à: a) Aplicação do método do ISLF em outros ambientes fluviais ou lagunares de distintas regiões do país, visando avaliar a aplicabilidade da metodologia apresentada; b) Desenvolvimento de trabalhos voltados à diferenciação da sensibilidade ao óleo das diversas espécies de vegetação que compõe as margens fluviais; c) Inserção da variável energia do fluxo da água, propiciando a identificação do potencial de concentração do óleo em determinadas regiões em virtude da morfologia dos rios e, d) Aprimoramento do ISLF considerando a inserção de variáveis dinâmicas na classificação das margens, como: nível, vazão e direção e intensidade dos ventos.

Agradecimentos. Ao $\mathrm{PRH}-27$ "Estudos Ambientais em Áreas de Atuação da Indústria do Petróleo" além da ANP, FINEP e Petrobras pelo apoio na formação proporcionada e o financiamento da bolsa. Também ao CNPQ pelo financiamento do Projeto CARTAS SAO - BACIA DE PELOTAS.

\section{Referências}

Adams, J.K., Heikamp, A.J. \& Hannah R.P. 1983. Method for ranking biological resources in oil spill response planning. In: THE OIL SPILL CONFERENCE, 1983, Washington, American Petroleum Institute, v. 1, 159-164.

Adler, E. \& Inbar, M. 2007. Shoreline sensitivity to oil spills, the Mediterranean coast of Israel: Assessment and analysis. Ocean \& Coastal Management, 50: 24-34.

Andrade, M.M.N., Szlafsztein, C.F., Souza Filho, 
P.W.M., Araujo, A.R. \& Gomes, M.K.T.A. 2010. A socioeconomic and natural vulnerability index for oil spills in an Amazonian harbor: A case study using GIS and remote sensing. Journal of Environmental Management, 91: 19721980.

ANP. Agência Nacional do Petróleo, Gás e Biocombustíveis. 2020. Indicadores de desempenho anuais. Disponível em: http:// www.anp.gov.br/exploracao-e-producaode-oleo-e-gas/seguranca-operacional-emeio-ambiente/dados-de-desempenho/ indicadores-de-desempenho. Consultado em 01/06/2020.

ANTAQ. Agência de Transportes Aquaviários. 2019. Anuário Estatístico Aquaviário. Disponível em: http://web.antaq.gov.br/ Anuario/ Consultado em 15/05/2020.

Araujo, S.I., Silva, G.H., \& Muehe, D. 2006. Mapas de sensibilidade ambiental a derramamentos de óleo: Ambientes costeiros, estuarinos e fluviais. Rio de Janeiro: Cenpes/Petrobras, 168p.

Azevedo, A., Fortunato, A.B., Epifanio, B., den Boer, S., Oliveira, E.R., Alves, F.L., Jesus, G., Gomes, J.L. \& Oliveira, A. 2017. An oil risk management system based on high-resolution hazard and vulnerability calculations. Ocean \& Coastal Management, 136: 1 - 18.

Baca, B.J., Michel, J., Kana, T.W., \& Maynard, N.G. 1983. Cape Fear River oil spill (North Carolina): Determining oil quantity from marsh surface area. In: THE OIL SPILL CONFERENCE, 1983, Washington, American Petroleum Institute, $v$. 1, 419-422.

Baca, B.J., Getter, C. D. \& Lindstedt-siva, J. 1985. Freshwater oil spill considerations: protection and cleanup. In: THE OIL SPILL CONFERENCE, 1985, Washington, American Petroleum Institute, v. 1, 385-390.

Ban, S.S.; Pressey, R.L. \& Graham, N.A.J. 2015. Assessing the effectiveness of local management of coral reefs using expert opinion and spatial Bayesian modeling. Plos one, 10(8): e0135465.

Boulhosa, M.B.M. \& Souza Filho, P.W.M. 2009. Reconhecimento e mapeamento dos ambientes costeiros para geração de mapas de ISA ao derramamento de óleo, Amazônia
Oriental. Revista Brasileira de Geofísica, 27(1): 23-37.

Cai, L., Yan, L., Ni, J. \& Wang, C., 2015. Assessment of Ecological Vulnerability under oil spill stress. Sustainnability, 7: 13073-13084.

Campo, A.G., 2017. Mapping environmental sensitivity: A systematic online approach to support environmental assessment and planning. Environmental Impact Assessment Review, 66: 86-98.

Cantagallo, C, Garcia, G.J. \& Milanelli, J.C. 2008. Mapeamento de sensibilidade ambiental a derramamentos de óleo do sistema estuarino de Santos, estado de São Paulo. Brazilian Journal of Aquatic Science and Technology, 12(2): 33-47.

Castanedo, S., Juanes, J.A., Medina, R., Puente, A., Fernandez, F., Olabarrieta, M. \& Pombo, C., 2009. Oil spill vulnerability assessment integration physical, biological and socioeconomical aspects: Application to the Cantabrian coast (Bay of Biscay, Spain). Journal of Environmental Management, 91(1), 149-159.

Castelão, R.M., Möller Jr., O.O. 2003. Sobre a circulação tridimensional forçada por ventos na Lagoa dos Patos. Atlântica, 25(2): 91-106.

Costa, D.M., Riedel, P.S., Cunha, C.M.L. \& Zambon, A.C. 2015. Utilização do Modelo Orientado à Representação do Pensamento Humano (MORPH) no estabelecimento do Índice de Sensibilidade Fluvial (ISF): uma proposta de contribuição à Classificação da Sensibilidade Ambiental ao Óleo. Pesquisas em Geociências, 42(1): 25-44.

EPA. Environmental Protection Agency. 2000. Inland Sensitivity Atlas - Reference Manual. Inland Sensitivity Mapping Project, 1(1): 91 p.

Fattal, P., Maanan, M., Tiller, I., Rollo, N., Robin, M. \& Pottier, P. 2010. Coastal vulnerability to oil spill pollution: the case of Noirmoutier Island (France). Journal of Coastal Research, 26(5): 879-887.

Ferreira, M.F. \& Beaumord, A.C. 2008. Mapeamento da sensibilidade ambiental a derrames de óleo nos cursos de água da bacia do rio Canhanduba, Itajaí, SC. Brazilian Journal of Aquatic Science and Technology, 12(2): 61-72. FZB. Fundação Zoobotânica do Rio Grande do 
Sul. 2014. Plano de Manejo de Parque Estadual Delta do Jacuí - Encarte II "Análise da UC". Fundação Zoobotânica RS: Porto Alegre, 158p.

GADEC. Gabinete da Defesa Civil de Porto Alegre. 2014. Medição Diária na Ilha da Pintada e Parque Harmonia. Disponível em: http:// www2. portoalegre.rs.gov.br/codec/default. php?p_secao=72. Consultado em 04/05/2017.

Gundlach, E.R. \& Hayes, M.O. 1978. Vulnerability of coastal environments to oil spill impacts. Marine Technology Society Journal, 12: 18-27. Gurnell, A.M., Bertoldi, W. \& Corenblit, D. 2012. Changing river channels: The roles of hydrological processes, plants and pioneer fluvial landforms in humid temperate, mixed load, gravel bed rivers. Earth-Science Reviews, 111: 129-141.

Hayes, M.O., Michel, J. \& Dahlin, J.A. 1995. Identifying and mapping sensitive resources for inland area planing. In: THE OIL SPILL CONFERENCE, 1995, Washington, American Petroleum Institute, v. 1, 365-371.

Hayes, M.O., Michel, J. \& Montello, T.M. 1997. The Reach Sensitivity Index (RSI) for Mapping Rivers and Streams. In: THE OIL SPILL CONFERENCE, 1997, Washington, American Petroleum Institute, v. 1, 343-350.

Hellea, I., Lecklinb, T., Jolmac, A., \& Kuikkaa, S. 2011. Modeling the effectiveness of oil combating from an ecological perspective $-\mathrm{A}$ Bayesian network for the Gulf of Finland; the Baltic Sea. Journal of Hazardous Materials, 185: 182-192.

IBAMA. Instituto Brasileiro do Meio Ambiente e Recursos Naturais. 2014. Relatório Acidentes Ambientais 2013. 31 p. Disponível em: http//www.ibama.gov.br. Consultado em 14/05/2020.

IBAMA. Instituto Brasileiro do Meio Ambiente e Recursos Naturais. 2015. Relatório Acidentes Ambientais 2014. 31 p. Disponível em: http//www.ibama.gov.br. Consultado em 13/05/2020.

IMO. International Maritime Organization. 2016. The global oil and gas industry Association for environmental and social issues International Association of Oil \& Gás Producers, 2016. Sensitivity mapping for oil spill response. IOGP Report Number 477. Londres.
Kankara, R.S., Arockiaraj, S. \& Prabhu, K., 2016. Environmental sensitivity mapping and risk assessment for oil spill along the Chennai Coast in India. Marine Pollution Bulletin, 106(12): 95-103.

Krueger, T., Page, T., Hubacek, K., Smith, L. \& Hiscock, K. 2012. The role of expert opinion in environmental modelling. Environmental Modelling \& Software, 36: 4-18.

Lawal, O. \& Oyegun, C.U., 2017. Geographic information systems-based expert system modelling for shoreline sensitivity to oil spill disaster in Rivers State, Nigeria. Jàmbá: Journal of Disaster Risk Studies, 9(1): a429.

Marinho, C., Nicolodi, J.L. 2019. Integração de parâmetros geomorfológicos e biológicos no desenvolvimento do Índice Integrado de Sensibilidade do Litoral (IISL). Revista Brasileira de Geografia Física, 12: 1509 - 1524.

Martin, T.G., Burgman, M.A., Fidler, F., Kuhnert, P.M., Loe-Choy, S. \& Mcbride, M. 2012. Eliciting Expert Knowledge in Conservation Science. Conservation Biology, 26: 29-38.

Martins, P.T.A., Riedel, P.S., Milanelli, J.C. \& Sturraro, J.R. 2014. Carta da Sensibilidade Ambiental ao Derramamento de Óleo em Rodovias: Aplicação Piloto na Estrada dos Tamoios (SP099), Estado de São Paulo. Revista Brasileira de Cartografia, 66(1): 59-74.

Melo, C.L., Bastos Neto, A.C., Caicedo, N.O.L. \& Schwarz, M.R. 2003. Contaminação do Lençol Freático pelo Vazamento de Óleo na Refinaria Presidente Getúlio Vargas - REPAR, Município de Araucária, Paraná. Revista Brasileira de Recursos Hídricos, 8(1): 13-19.

Mendes, R.F., Minniti, V., Lopes, C.F., Milanelli, J.C., Torres, C., Yogui, R., Rodrigues, G. \& Mariz, E. 2005. Elaboração de Metodologia para Análise dos Riscos Ambientais. In: RIO PIPELINE CONFERENCE \& EXPOSITION. Anais. Rio de Janeiro, v. 1. CD-ROOM.

Michel, J., Hayes, M., Dahlin, J. \& Barton, K. 1994. Sensitivity Mapping of Inland Areas: Technical Support to the Inland Areas Planning Committee Working Group, HAZMAT Report 95-4, NOAA Hazardous Materials Response and Assessment Div., Washington, D.C., 54 p.

MMA. Ministério do Meio Ambiente. 2007. Especificações e Normas Técnicas para 
Elaboração de Cartas de Sensibilidade Ambiental para Derramamentos de Óleo. Ministério do Meio Ambiente, Secretaria de Mudanças Climáticas e Qualidade Ambiental, Gerência de Qualidade Costeira do Ar. 107p.

MMA. Ministério do Meio Ambiente. 2016. Atlas de sensibilidade ambiental ao óleo da Bacia Marítima de Pelotas. Porto Alegre. Ed. Panorama Crítico. 116p.

Moller, O.O., Lorenzetti, J.A., Stech, J.L. \& Mata, M. 1996. The Patos Lagoon summertime circulation and dynamics. Continental Shelf Research, 16(3): 335-351.

Munhoz, E.S., Christmann, L.C., Lima, J.B., Limberger, D.C.H. 2017. Serviços ambientais e o Delta do Jacuí. Revista Eletrônica Científica da UERGS, 3(4): 704-710.

Muller, M., Romero, A.F., Riedel, P.S. \& Perinotto, R.R.C. 2011. Ações de Resposta para Emergência em caso de Derrames de Óleo no Mar e Proposta de Implementação de Sistema de Informação voltado à Sensibilidade Ambiental para o Litoral Sul Paulista, Brasil. Revista da Gestão Costeira Integrada, 11(4): 397-407.

Nicolodi, J.L., Toldo, E.E. \& Farina, L. 2010. Dinâmica e ressuspensão por ondas no Lago Guaíba (RS, Brasil) e implicações nos locais de captação de água para abastecimento humano. Pesquisas em Geociências, 37: 2539.

NOOA. National Oceanic and Atmosferic Administration. 2002. Environmental sensitivity index guidelines, Version 3.0. NOAA Technical Memorandum. Seatle: Hazardous Materials Response and Assessment Division, $89 \mathrm{p}$.

NOOA. National Oceanic and Atmosferic Administration. 2004. Sensitivity of Estuarine and Riverine Environments and Wildlife to Spilled Oil Columbia River Atlas. NOAA Technical Memorandum. Seatle: Hazardous Materials Response and Assessment Division.

NOOA. National Oceanic and Atmosferic Administration. 2006. Hudson River. Resource Atlas NOAA Technical Memorandum. Seatle: Hazardous Materials Response and Assessment Division.

NOOA. National Oceanic and Atmosferic
Administration. 2019. Petersen, J., et al. 2019. Environmental Sensitivity Index Guidelines, Version 4.0. NOAA Technical Memorandum NOS OR\&R 52.

Nelson, J.R., Grubesic, T.H., Sim, L., Rose, K. \& Graham, J. 2015. Approach for Assessing Coastal Vulnerability to Oil Spills for Prevention and Readiness Using GIS and the Blowout and Spill Occurrence Model. Ocean and Coastal Management, 11:1-11.

Nelson, J.R. \& Grubesic, T.H. 2017. Oil spill modeling: Risk, spatial vulnerability, and impact assessment. Progress in Physical Geography: Earth and Environment, 42(1): 112-127.

Oliveira, M.L.A. 2007. Fatores condicionantes da distribuição espacial de comunidades vegetais no Parque Estadual Delta do Jacuí, Rio Grande do Sul. In: CONGRESSO NACIONAL DE BOTÂNICA, Blumenau. Anais. v. 1, p. 250.

Oliveira, E.B. \& Nicolodi, J.L. 2016. Oil permeability variations on lagoon sand beaches in the Patos-Guaíba system in Rio Grande do Sul, Brazil. Marine Pollution Bulletin, 115(1-2): 154-163.

Parviainen, T., Lehikoinen, A., Kuikka, S. \& Haapasaari, P. 2019. Risk frames and multiple ways of knowing: Coping with ambiguity in oil spill risk governance in the Norwegian Barents Sea. Environmental Science \& Policy, 98: 95111.

Pincinato, F.L., Riedel, P.S. \& Milanelli, J.C. 2009. Modelling an expert GIS system based on knowledge to evaluate oil spill environmental sensitivity. Ocean \& Coastal Management, 52: 479-486.

Scottá, F.C., Andrade, M.M., Silva Jr., V.O., Oliveira, N., Weschenfelder, J., Bortolin, E.C. \& Nunes, J.C. 2019. Geoacoustic patterns of the Guaiba river bottom and sub-botton and their relationship with sedimentary and hydrodynamic processes. Brazilian Journal of Geophysics, 37(1): 105-120.

Souza Filho, P.W.M., Prost, T.R.C., Miranda, A,F.P., Sales, M.E.C., Borges, S, H.V., Costa, F.R., Almeida, E.F. \& Nascimento Jr, W.R. 2009. Environmental Sensitivity Index (ESI) mapping of oil spill in the Amazon coastal zone: the PIATAM mar project. Revista Brasileira de Geofísica, 27(1): 7-22. 
Thomaz, S.M., Roberto, M.C. \& Bini, L.M. 1997. Caracterização limnológica dos ambientes aquáticoseinfluência dosníveisfluviométricos. In: Vazzoler, A.E.A.M.; Agostinho, A.A.; Hahn, N.S. (Eds.). A planície de inundação do alto rio Paraná: aspectos físicos, biológicos e socioeconomicos. Maringá, EDUEM, p. 73102.

Tomazelli, L.J. \& Villwock, J.A. 2005. Mapeamento Geológico de Planície Costeiras: o Exemplo da Costa do Rio Grande do Sul. Revista Gravel, (3): 109-115.

Tsahalis, D.T. 1979. Contingency planning for oil spills: RIVERSPILL-a river simulation model. In: THE OIL SPILL CONFERENCE, 1979, Washington, American Petroleum Institute, $v$. 1, 27-36

Vasconcelos, T.L., Barbosa, C.C.A., Valdevino, D.S. \& Sá, L.A.C.M. 2010. Cartas de Sensibilidade Ambiental ao Derramamento de Óleo e sua distribuição no Brasil. In: SIMPÓSIO BRASILEIRO DE CIÊNCIAS GEODÉSICAS E TECNOLOGIA DA GEOINFORMAÇÃO, Recife. Anais. v. 1, CD-ROOM.

Wieczoreck, A., Dias-Brito, D. \& Milanelli, J.C. 2007. Mapping oil spill environmental sensitivity in Cardoso Island State Park and surroundings areas, São Paulo, Brazil. Ocean \& Coastal Management, 50: 872-886.

Zancan Filho, L.C. \& Quadros, T.F.P. 2017. Efeito da dinâmica fluvial e da ação antrópica sobre a erosão de margens fluviais: o caso da mineração de areia no Rio Jacuí. Revista de Ciências Ambientais, 11(1): 49-64.

Zengel, S., Hayes, M.O., Michel, J., White, M., Benggio, M.E., Lopez, F. \& Ouw, S. 2001. Integrated Planning From the Mountains to the Sea: Environmental Sensitivity Mapping In the Caribbean. In: THE OIL SPILL CONFERENCE, 2001, Washington, American Petroleum Institute, v. 2, 1113-1117. 